\title{
Study on Factors Affecting the Development of Urban Spatial Structure in Xi'an Since 1995
}

\author{
Ye Tian \\ School of Architecture \\ Xi'an University of Architecture \& Technology \\ Xi'an, China \\ tianye981@126.com
}

\author{
Qi Zu \\ School of Architecture \\ Xi'an University of Architecture \& Technology \\ Xi'an, China \\ shumiyapi@163.com
}

\begin{abstract}
Xi'an has a long history and rich culture. It is China's inland center city, and also the typical of the inland cities. Development of Xi'an urban spatial structure follows the urban master plan, its development process could be divided into four various stages. It is a process: a single center-multi center-circle Multicore. Since 1995, the urban spatial structure in Xi'an changes mostly. This time is the most representative. Factors affecting the development of urban spatial structure in Xi'an can be divided into explicit factors, such as social and economic factors, major projects, new construction and urban transport development etc; and implicit factors like national and regional policies, globalization and information technology and other. These two factors mix, and promote the development of $\mathrm{Xi}^{\prime}$ an urban spatial structure.
\end{abstract}

Keywords-since 1995; Xi 'an; the development of urban spatial structure; process and characteristics; affecting factors

\section{INTRODUCTION}

$\mathrm{Xi}$ 'an is a international famous historical and cultural city. It has the urban construction of more than five thousand years. Xi'an is the capital of 13 dynasties. Xi 'an urban spatial form has a unique flavor. Xi'an city is the core of the western region. The study of Xi'an can further enhance the international influence of Xi'an, and more importantly can let people all over the world to learn more about xi 'an, to understand the west.

\section{THE PROCESS OF URBAN SPATIAL STRUCTURE} DEVELOPMENT AND ITS CHARACTERISTICS IN XI 'AN BASED ON THE URBAN MASTER PLAN

A. The Process of Urban Spatial Structure Development in Xi 'an Based on the Urban Master Plan

Since 1949, based on China's social political and economic system, the development of the city is under the unified arrangement of the country. Arranged for city, these ideas embodied in the urban master plan of the city. Development of xi 'an urban spatial structure has changed under the guidance of the urban master plan in Xi'an 4 times. With the changes of the urban social and economy, the urban master plan could constantly be up-to-date. So the influence of the urban master plan can have effect until the next new one has done.

The first urban master plan of Xi'an (19531972) established the pattern of the city: textile City in the eastern, western Electronic City and the southern suburbs of cultural and educational areas. Construction of the city had to avoid the Zhou, Qin, Han and Tang 4 sites zones, and followed Tang checkerboard pattern of Chang'an City as a whole road network and the axis of symmetry. This urban spatial structure has been maintained to 1980 (see in Fig .1);

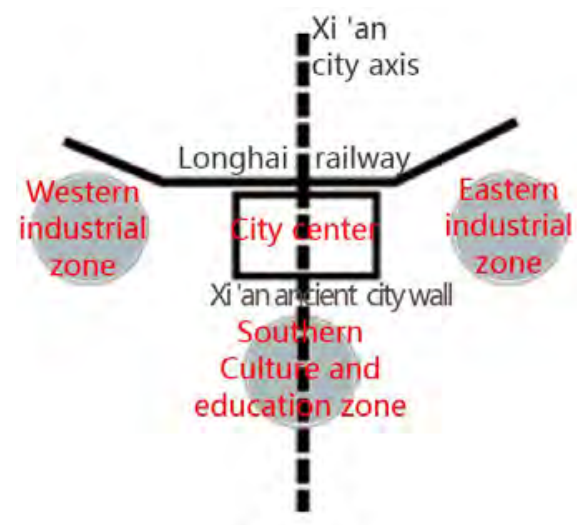

1980

Figure 1. The Urban Spatial Structure in Xi'an 1980

Second urban master plan of Xi'an (1980-2000) established the Ming city center. Chang'an city's layout features: checkerboard road network and the axis of symmetry have been retained. It maintains strict pattern out of the city, based on the protection of Zhou, Qin, Han and Tang 4 sites zones, and chooses new structural model of development around the old city. In the outskirts of the city, new districts including Xi'an hi-tech industriec development zone and $\mathrm{Xi}$ 'an economic and technological Industrial development zone built up. City developed direct to the southwest, north, forming the city's spatial structure in 1995 (see in Fig .2).

Third Xi'an urban master plan (1995-2010) had to maintain and develop the traditional urban pattern and style. It determines the structure and layout of Xi'an city form for "center group, peripheral group, the axial location, banded development". Connected with urban expressway between city group, each of them has own characteristics and develops independently; Between the Center city and the groups is green belt. The urban road network layout inherits tang Chang'an grid pattern. Protection of urban development axis must have done, in order to determine the Ming Xi'an city as the main axis line of the urban central axis. In the outskirts of the city, 
new districts including Xi'an Qujiang new district and Xi'an Chan-ba ecological district built up (see in Fig .3).

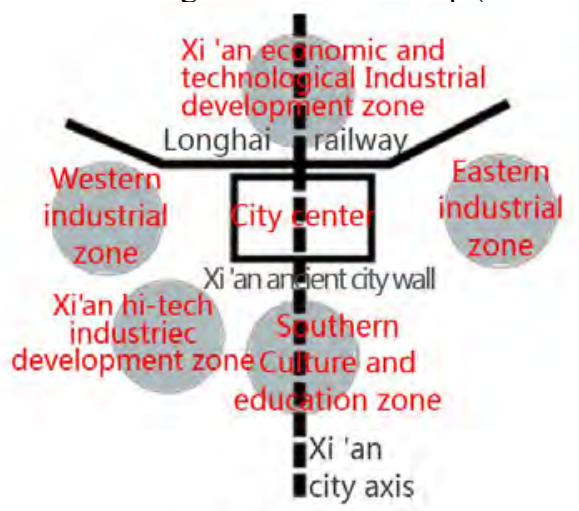

1995

Figure 2. The Urban Spatial Structure in Xi'an 1995

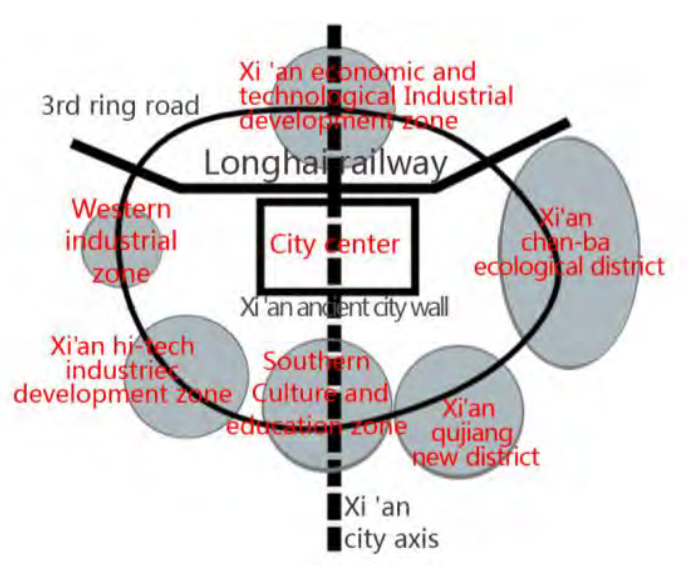

2004

Figure 3. The Urban Spatial Structure in Xi'an 2004

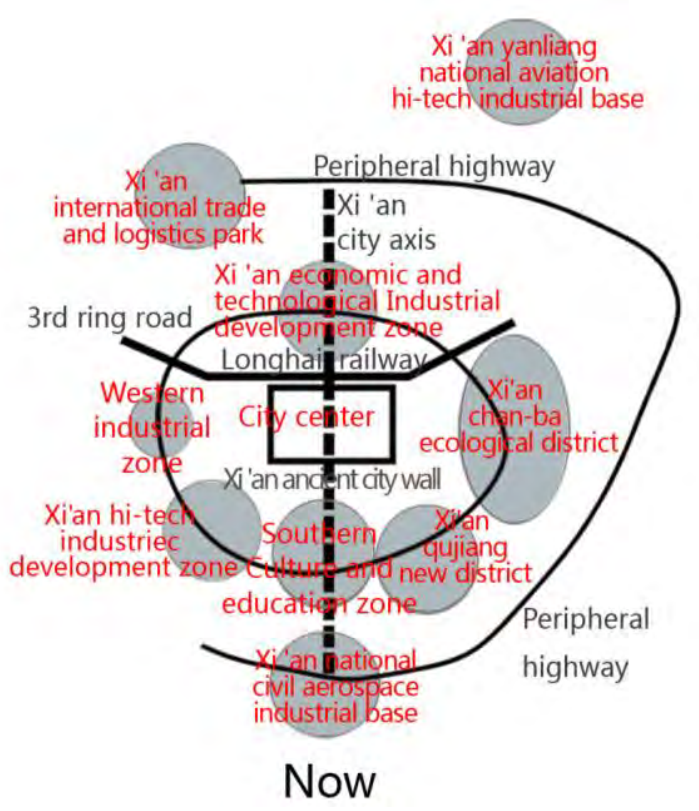

Figure 4. The Urban Spatial Structure in Xi'an Now
With the ever-changing external environment, the city develops rapidly in Xi'an. Beginning in 2004, Xi'an begins to prepare the fourth overall planning. Although the fourth Xi'an City urban master plan (2008-2020) marked the beginning of the 2008, but in 2004 it began to have begun to play a role. Fourth urban master plan combined Xi'an situation, has a comprehensive analysis of Xi'an land conditions and socio-economic development environment, to determine the overall structure and layout of $\mathrm{Xi}^{\prime}$ an form as "Nine-palace pattern, checkerboard road network, the axis prominent, a city suspicious" shape pattern. Accordin $\mathrm{g}$ to Xi'an own conditions, it has set up Xi'an national civil aerospace industrial base, $\mathrm{Xi}$ 'an Yanliang national aviation hi-tech industrial base and Xi'an international trade and logistics park and other new area in the outskirts of the city constantly, and convergence with ring road and highways (see in Fig .4).

\section{B. Characteristics of Urban spatial structure development in $\mathrm{Xi}^{\prime}$ an}

- Epitomizes the city center from Single centermulti center-circle Multicore;

- Take the urban master plan as a guide;

- Inheritance and development pattern of Chang'an City, protecting the ancient city has been the same.

- Follow the trend of the times, with its own advantages, and constantly building new district, the new district is the main driving force for the development of Xi'an urban spatial structure;

- Since 1995, the urban spatial structure in Xi'an changes mostly. This time is the most representative.

\section{FACTORS AFFECTING THE DEVELOPMENT OF URBAN SPATIAL STRUCTURE IN XI 'AN SINCE 1995}

Since 1995, with the information technology and globalization progresses, the city entered the era of rapid development, Xi'an is no exception. Significant changes highlighted in Xi'an urban spatial structure occurs, and its severity and speed of the change are unprecedented. Since 1995, there are many factors that have affected the development of Xi'an urban spatial structure, both explicit and implicit. They worked together to promote the development and evolution of the spatial structure of the city of Xi'an.

\section{A. Explicit affecting factor}

1) social, economic and demographic changes affect profound

Since 1995, Xi'an's economy, population and built-up areas grow significant. They promote the development of the city, and produce a deciding factor of Xi'an urban spatial structure changes (see in tab. 1).

2) Significantly affected by natural and geographical conditions

The development of Xi'an is restricted to its own conditions, including the Chan-ba Delta, Jing- wei Delta, and other wetlands, greenbelt, river and lake water lines within the area of flood control, natural plateau slope, urban construction and unsuitable ground fissures and fault zone and other areas and so on. All of them limit the development direction of the city. 
TABLE I. THE TOTAL POPULATION, GDP, AND BUILT-UP AREA

\begin{tabular}{|c|c|c|c|}
\hline Year & $\begin{array}{c}\text { The total } \\
\text { population } \\
\text { (Unit: } \\
\text { thousand) }\end{array}$ & $\begin{array}{c}\text { GDP (Unit: } \\
\text { billion Yuan) }\end{array}$ & $\begin{array}{c}\text { Built-up area } \\
\text { (Units: square } \\
\text { kilometer) }\end{array}$ \\
\hline 1995 & 6482.1 & 33.035 & 148 \\
\hline 1996 & 6548.7 & 40.695 & 148 \\
\hline 1997 & 6620.6 & 48.882 & 162 \\
\hline 1998 & 6682.2 & 52.585 & 162 \\
\hline 1999 & 6745 & 57.729 & 187 \\
\hline 2000 & 6880.1 & 64.613 & 187 \\
\hline 2001 & 6948.4 & 73.486 & 187 \\
\hline 2002 & 7025.9 & 82.668 & 187 \\
\hline 2003 & 7165.8 & 94.666 & 204 \\
\hline 2004 & 7250.1 & 110.239 & 221.74 \\
\hline 2005 & 7417.3 & 127.014 & 230.71 \\
\hline 2006 & 7531.1 & 147.335 & 261.40 \\
\hline 2007 & 7642.5 & 173.71 & 267.91 \\
\hline 2008 & 7723 & 219 & 272.71 \\
\hline 2009 & 7816.7 & 271.91 & 283.1 \\
\hline 2010 & 7827.3 & 324.149 & 331 \\
\hline 2011 & 7918.3 & 386.4 & 342.55 \\
\hline 2012 & 7959.8 & 436.337 & 359 \\
\hline 2013 & 8069.3 & 488.41 & 359 \\
\hline
\end{tabular}

3) Numerous cultural relics

Xi'an is rich in heritage. Xi'an has state-level cultural relics protection units 34,72 provincial-level cultural relics protection units, and 2944 registered point relics . There is also a certain amount of historical and cultural blocks and so on. Xi'an exists large protected area sites and key cultural relics protection units. They have been restricted the development of it in order to ensure their coordination with the relics.

4) Major projects will have a significant affecting on the development of Xi'an urban spatial structure

Xi'an's administrative center moved northward, which plays a decisive role in urban development. It will have an impact on the surrounding area, making the surrounding area into a new administrative office. Construction of Chan-ba basin, will expand the development space of the city in the east; construction of high-tech zones will accelerate the development in southwestern region.

\section{5) Construction of new district}

Construction and development of new district is important source of power to promote the evolution of Xi'an urban spatial structure; it is an important reason to promote industrial space optimization and social space differentiation. Xi'an has built 7 new districts. They are $\mathrm{Xi}$ 'an hi-tech industriec development zone, $\mathrm{Xi}$ 'an economic and technological Industrial development zone, Xi'an Qujiang new district, Xi'an Chan-ba ecological district, Xi'an national civil aerospace industrial base, Xi'an Yanliang national aviation hi-tech industrial base and Xi'an international trade and logistics park. They promote the development of the city rapidly, and have played a decisive role on the development of urban spatial structure.

6) Development of urban transport

In the 21 st century, the rapid development of China's urban transportation, greatly promoted the overall development process of the city. Emergence of various types of urban transportation has brought tremendous changes in the flow. It greatly improved its accessibility along and changed its geographic conditions. Thus it affected urban land use and the industrial layout, thereby the urban spatial structure and morphology. Experiences at home and abroad, show that the spatial structure of the city is often the result of transport development strategy and spatial development strategies interaction. Development of transport prompted the urban spatial structure adjustment, and accelerated differentiation reorganization of urban space.

\section{B. Implicit affecting factors}

1) Policies and regulations from countries and regions

\section{a) Western Development Strategy}

Since 1999, the state launched the western development strategy, development of Xi'an grew rapidly. Xi'an has a good industrial base and material and technical conditions. This determines that it play a leading role in advancing the development of the western region. Favorable national policy provides a good foundation for the development of Xi'an city.

\section{b) "One line two belts" strategy from Shaanxi} Province

In 2001, the ministry approved Xi'an as the center, and took Longhai-Lanxin railway and Bao-tong highway as the axis, plans to build a national high-tech industrial development zone and Spark industrial belt. On this basis, Shaanxi Province launched "One line two belts" strategy. This provides opportunities for Xi'an's development and industrial restructuring.

\section{c) Xi'an-Xianyang integration strategy}

Xian takes Xi'an-Xianyang industry build area as a breakthrough, to achieve "one industry isomorphic and urban functions complementary" target. Two cities cooperate in terms of planning, transport, information, market, industry, science, education, tourism, environment and so on, to enhance the radiation and leading role on the surrounding economy, meanwhile promote the development of their own city.

\section{2) Globalization and information technology}

Development in today's world is mainly two trends of globalization and information technology. Since the 1990s, the rapid development of the Internet greatly changed people's way of life, but also intensified the process of economic globalization. The impact of globalization information technology on urban and regional development is growing, the application of information 
industry development, and information networks is accelerating change the original urban and regional spatial structure.

On the one hand, development of globalization and information technology enhances the regional activities of the freedom of choice of urban, industrial layout, space constraints government zoning and residential location choice narrowed.

On the other hand, development of globalization and information technology break the traditional "coreperiphery" model of urban spatial structure, formed new era under the agglomeration and diffusion. Such as finance, information services, management functions were gathering to the heart posture, and general functional areas of residence, industrial and other cities were dispersed trend. Meanwhile, the development of information networks makes the link between the city more closely to promote the formation of network-based urban system.

\section{3) Eco-city concept}

Eco-city is the advanced stage of urban development. It presents a series of countermeasures to solve the city's disease, and establish natural harmony, social justice, economic efficiency, win-win situation between man and nature ideal city model. Not only does it give us life livable environment, but also to create a harmonious cultural environment. It emphasizes the ecological standards of the city, and pursues harmony and efficiency of urban systems. Xi'an from its own advantages and strategic future urban development point of view, determines to build an ecological city in the future.

\section{CONCLUSIONS}

In summary, the urban spatial structure is not only a physical manifestation of the city-state, style and layout. It also the combined result of city's political, historical, cultural, social, economic and geographic. It is materialized course of human events, and always in a change in the dynamic development of the process. Only a timely summary of the evolution of urban spatial structure, characteristics and influencing factors, can effectively grasp the context of urban development, rational development of new urban development space, effectively guide urban health and sustainable development. By analyzing the factors affecting the development of urban spatial structure of Xi'an since 1995, and combining with the current situation in Xi'an, Author hopes to benefit urban development in Xi'an, and provide a reference for related research.

\section{REFERENCES}

[1] Jin Duan, Urban Spatial Development Theory. Nanjing, China: Jiangsu science and Technology Press, 1999. (In Chinese)

[2] Xingzhong Wang, The Research of Chinese Urban Social Spatial Structure. Beijing, China: Science Press, 2000(In Chinese)

[3] Report on the Work of Xi'an Municipal Government 2002 2013, http://www.xa.gov.cn(In Chinese)

[4] Yaping Huang, Urban Spatial Theories and Urban Spatial Analysis. Nanjing, China: Southeast University Press, 2002. (In Chinese)

[5] Hongling Su and Pei Zhang, Study on the Competitiveness of Urban Spatial Structure. Journal of Xi'an University of Architecture \&technology, vol.35(3), Sep. 2003, pp. 226-230 (In Chinese)

[6] Jian Feng and Yixing Zhou, A Review and Prospect on Urban Internal Spatial Structure Research in China. Progress in Geography, vol.22(3), Jun. 2003, pp. 304-315. (In Chinese)

[7] Summary of Xi'an Urban Master Plan (2008-2020), http://www.xaghj.gov.cn (In Chinese)

[8] Yunying Ren. Development of Urban Planning Conception in Modern Xi an-A Case Study of the File Documents by the 1927 1947 Republic of China. Journal of Shaanxi Normal University 'Philosophy and social sciences', vol.38(5), Sep. 2009, pp. 105-112. (In Chinese)

[9] Yanling Li, Based on Social Space Structure of Urban Social Regional Evolution and Spatial Structure Research. Xi'an, China: Xi'an International Studies University, 2011(In Chinese)

[10] Changdong Ye, Chunshan Zhou and Zhen Li. Supply-demand Analysis of Urban New District Development. City Planning Review, vol. 36 (7), Jul. 2012, pp. 32-37, 72. (In Chinese)

[11] Lanqin Xing, Xi'an Urban Spatial Structure Based on Sustainable Development Research. Xi'an, China: Northwest University, 2012(In Chinese)

[12] Changdong Ye and Chunshan Zhou, Evolution of Urban Spatial Structure in Chinese Mega-Cities in Recent 20 Years. Urban Development Studies, vol. 21 (3), Mar. 2014, pp. 28-34. (In Chinese) 